\title{
USING PARTICLE SWARM OPTIMIZATION TO ESTABLISH A LOCAL GEOMETRIC GEOID MODEL
}

\section{Do Uso do Método de Otimização por Exame de Partículas para Estimar um Modelo Local do Geoide Geométrico}

\author{
Szu-Pyng Kao ${ }^{1}$ \\ Fang-Shii Ning ${ }^{2}$ \\ Chao-Nan Chen ${ }^{1}$ \\ Chia-Ling Chen ${ }^{1}$
}

1 Department of Civil Engineering, National Chung Hsing University. No.145, Xingda Rd., South
District,Taichung City 402, Taiwan.
E-mail: spkao@dragon.nchu.edu.tw;ccn_chen@yahoo.com.tw; c21342001@yahoo.com.tw
2 Department of Land Economics, National Chengchi University.NO.64, Sec.2, ZhiNan Rd., Wenshan
District, Taipei $11605, T a i w a n$.
E-mail: $\underline{\text { fsn@nccu.edu.tw }}$

\section{Abstract:}

There exist a number of methods for approximating the local geoid surface and studies carried out to determine a local geoid. In this study, performance of geoid by PSO method in modeling local geoid was presented and analyzed. The ellipsoidal heights (h), derived from GPS observations, and known orthometric heights from first-order bench marks were first used to create local geometric geoid model, then the PSO method was used to convert ellipsoidal heights into orthometric heights $(\mathrm{H})$. The resulting values were used to compare between the spirit leveling and GPS methods. The adopted PSO method can improve the fitting of local geometric geoid by quadratic surface fitting method, which agrees with the known orthometric heights within $\pm 1.02 \mathrm{~cm}$ the Cartography produced: General Map, Partial Maps, Profile, Cross Sections and others.

Keywords: Particle swarm optimization (PSO); Quadratic surface fitting; Ellipsoidal height; Orthometric height.

\section{Resumo:}

Existe uma série de métodos para aproximar a superfície do geoide local bem como vários estudos conduzidos para determinar um geoide local. Neste estudo, apresentou-se e analisou-se o desempenho do geoide pelo método de otimização por exame de partículas (PSO, do inglês Particle Swarm Optimization) na modelagem do geoide local. As altitudes elipsoidais (h), derivada de observações GPS, e altitudes ortométricas de referências de nível de primeira ordem foram usados para criar um modelo do geoide geométrica local, na sequencia usou-se o método PSO para converter altitudes elipsoidais em altitudes ortométricas $(\mathrm{H})$. Os valores estimados foram comparados com valores provenientes de nivelamento geométrico e levantamento GPS. O 
método PSO foi capaz de melhorar a adaptação do geoide local pelo método de ajustamento de superfície quadrática e apresentou diferenças da ordem de $\pm 1,02 \mathrm{~cm}$ em relação a altitudes ortométricas observadas.

Palavras-chave: Otimização por Enxame de Partículas (PSO); Geoide geométrico local; GPS.

\section{Introduction}

Numerous studies have investigated the development of suitable local geoid undulation models by applying various fitting methods to measurements of ellipsoidal height $\mathrm{h}$ and leveling orthometric height $\mathrm{H}$ obtained using global positioning systems (GPSs) (Odera et al., 2014; Abdalla et al., 2011; Abdalla and Fairhead, 2011; Akcin and Celik, 2013; Abdalla, 2009; Featherstone et al., 2004; Kao et al., 2014 ; Kao, 2006; Kotsakis and Sideris, 1999; Kao and Bethel, 1992(a); Kao and Bethel, 1992(b); Ning, 2015; Lin, 2007; Tranes et al., 2007; Kiamehr, 2006; Ustun and Demirel, 2006; You, 2006; Yang and Chen, 1999). The geoid of each position in a location can be calculated to determine $\mathrm{H}$ for each position. According to a review of research related to the fitting of geoid undulation models, surface fitting has been performed with least squares collocation, neural networks, second-order curve-surface fitting, back-propagation neural networks (Akcin and Celik, 2013), multisurface function methods, genetic algorithms, least-squares support vector machines (Shen, 2011), and other artificial intelligence methods (Abdalla and Green, 2016; Abdalla and Elmahal, 2016; Daras, 2008; Ellmann, 2001; Ulotu, 2009). The fitting processes used in these geoid undulation modeling methods necessitate extensive computation and complex program development. Thus, in the present study, particle swarm optimization (PSO) was employed to compute the coefficients of a quadratic surfacefitting model to effectively improve the prediction accuracy of local geometric geoids. PSO is among the relatively simpler artificial intelligence methods, with the characteristics of having few parameters to configure; rapid convergence, memorability, and global and local search abilities; and applicability in dynamic environments. Compared with other artificial intelligence algorithms, PSO offers the advantages of lower complexity, easier programming, and faster convergence. Hence, the present study adopted PSO to overcome the limitations and disadvantages of other fitting methods to minimize parameter setup, simplify the program development process, and achieve superior accuracy in GPS/leveling measurements of orthometric height $\mathrm{H}$.

\section{PSO Fitting Procedure}

Mathematical model fitting involves placing partial GPS positions on benchmarks with known $\mathrm{H}$ elevations or using the spirit leveling method to determine the benchmark elevation of partial GPS positions to ensure that each benchmark consists of ellipsoidal height $h$ and benchmark elevation $\mathrm{H}$, from which a local geoid $\mathrm{N}$ mathematic model is established. These points are used in the fitting process to obtain the geometrical geoid values NGPS and benchmark elevations $\mathrm{H}$. The orthometric height of any external point in a study area is derived on the basis of the root mean square error (RMSE) of the fitting model. Previous research showed that the optimal 
surface equation for fitting a geoid undulation is the quadratic surface equation, under consideration of economy and simplicity (Ning, 2015). Accordingly, the present study combined the quadratic surface method with PSO to determine local geometrical geoids through the following step-by-step method.

\subsection{Quadratic Surface-Fitting Method}

The polynomial method is one of the most widely used methods for expressing a study area as a single function. This method involves generating constant coefficients by using reference points with known values to form a geoid surface model; moreover, new points with unknown values can be calculated using these constant coefficients (Ning, 2015). Accordingly, the present study employed the quadratic surface-fitting method to fit the local geometrical geoid value $\mathrm{Ni}$ of an experimental region, which was compared with a known local geometrical geoid value Nn.

The quadratic polynomial function expressed in Equation 1 was used as the surface-fitting model:

$$
N_{i}=a_{0}+a_{1} x_{i}+a_{2} y_{i}+a_{3} x_{i}^{2}+a_{4} y_{i}^{2}+a_{5} x_{i} y_{i}
$$

where $x i, y i$ are the plane Cartesian coordinates; $\mathrm{Ni}$ is the local geometric geoid value in the fitting area of the corresponding fitting point; and $\left(a_{0}, a_{1}, a_{2}, \ldots a 5\right)$ are undetermined coefficients.

The principle of the quadratic surface-fitting method involves using data of level coincident points with $n(\mathrm{n} \geq 6)$ known local geometrical geoid values within the test location, as well as applying the minimum least squares method. The undetermined coefficients $a_{0}, a_{1}, a_{2}, \ldots a_{5}$ are solved using repeated iteration cycles and fitted to the quadratic surface-fitting model. Subsequently, the model's coefficients are determined and the geometrical geoid value $\mathrm{Ni}$ is calculated.

In the present study, a local geometrical geoid mathematical model was established through the aforementioned steps. Thus, for the calculation process, only GPS measurements of the planar position $(x, y)$ and ellipsoidal height $\mathrm{h}$ of arbitrary unknown positions were required in order to directly apply the quadratic surface-fitting method and determine the geometrical geoid value $\mathrm{Ni}$ of the arbitrary unknown position. The orthometric elevation $H$ was obtained by subtracting the ellipsoidal height $h$ from the geometrical geoid value $N i$ at the same arbitrary unknown position. When a local geometrical geoid value $N i$ is obtained using the quadratic surface-fitting method with a known local geometric geoid value $N k$, the corresponding residual matrix vg can be expressed as shown in Equation 2:

$$
v_{s}=N_{i}-N_{k}
$$

Equation 2 can be used to obtain the RMSE, as shown in Equation 3:

$$
R M S E=\sqrt{\frac{v_{g}^{t} v_{g}}{n}}
$$

where vg represents the difference between the fitted local geometric geoid value of the checkpoint and the known geometrical geoid value $N k$, and $n$ represents the number of 
checkpoints. This study used the RMSE index to evaluate the accuracy of the fitted local geometric geoid model.

\subsection{Quadratic Surface-Fitting Method}

PSO was proposed by Kennedy and Eberhart (1995). The concept of the algorithm was based on swarm behavior and applied to optimization problems. Every particle in the PSO solution space is a candidate solution to the problem. The fitness values of each candidate solution are determined by optimizing the function setup, which guides swarms toward superior evolution. Each particle refers to the optimal experience of the swarm (group best; gbest) in addition to its own experience (personal best; pbest) to determine the location and distance searched. By exchanging individual experiences, the particles gradually approach a target solution. To enhance the PSO algorithm, the present study followed EBERHART and SHI (1998) in using an inertia weight to gradually adjust the particle velocity, which increases the likelihood of searching different locations and thereby avoids being trapped in a local optimal solution when rapid particle convergence occurs. Thus, in the present study, the particle velocity was set to an initial value of 0.9 with a gradual linear decrease to 0.4 . A study by Kennedy and Eberhart (1995) was also referenced; they found that when the weighting factors had identical values, meaning that the particles possessed the same weighting during self-searches, the optimized value was 1.494 .

\section{Methods and procedures}

\subsection{Research Data and Collection}

The data of the experimental location selected for this study were the Cartesian coordinates $(x, y)$ and ellipsoidal heights $h$ of each benchmark measured using GPS. The benchmark orthometric heights $H$ are accurate to first-order, Class II leveling. The benchmarks distributions are shown in Figure 1. 


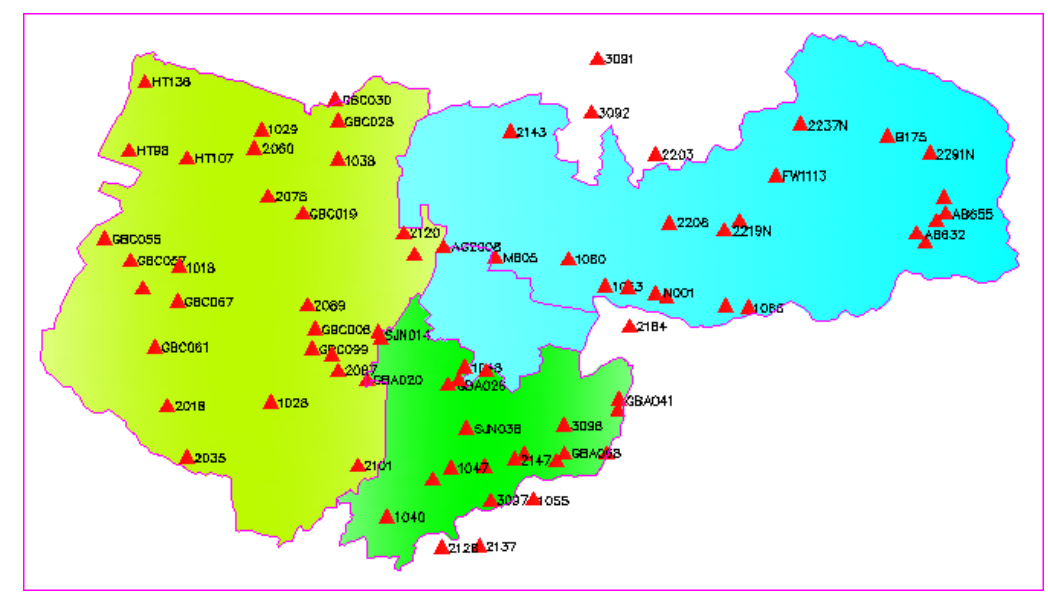

Figure 1: Distribution of 78 GPS/leveling stations in test area (triangles represent stations where leveling and GPS data were obtained)

\subsection{Procedures}

First, a program developed by the authors was used to read and treat the position coordinates ( $x$, $y$ ) as particles in PSO. Each geoid undulation surface comprised $(n+1)$ sets of independent variables $(x 1, y 1),(x 2, y 2), \ldots,(x n+1, y n+1)$. Each independent variable corresponds to a coordinate on the quadratic surface. PSO was used to update the position of each quadratic polynomial function coefficient where the position coordinates remain unchanged. The magnitude of RMSE was calculated to evaluate the fitness function, compare the current gbest with the previous pbest (to determine the subsequent gbest and pbest iterations), and update the local geoid undulation quadratic polynomial function coefficient by using PSO. The optimized minimum RMSE and local geoid model were obtained after repeated iteration cycles.

The step-by-step PSO search procedures for the local geometric geoid model are described as follows:

(a) For the first iteration, use the program to read the coordinates of a position and fit the quadratic polynomial function of the geoid undulation. Each function consists of six coefficients $\left(\left(a_{0}, a_{1}, a_{2}, \ldots a_{5}\right)\right.$.

(b) Solve all quadratic polynomial function calculations and determine the fitness function value RMSE of all geoid undulations.

(c) Determine the subsequent iteration of the PSO best value by comparing the RMSE fitness functions.

(d) Update the program coefficients.

(e) Establish the quadratic polynomial function and RMSE fitness function of the new geoid undulation.

(f) Repeat Steps (c)-(e).

(g) Solve the optimized RMSE and geoid undulation model when the maximum number of iterations is reached (500 in this program).

(h) Terminate the program. 


\section{Discussion: Test Area, Data, and Results}

\subsection{Test Data: Topographical Map of the Study Area}

The experimental area covered $160 \mathrm{~km} 2$ of gentle terrain without substantial topographic relief. The area featured a sufficient density of coincident points, with one control point located within $2 \mathrm{~km} 2$ on average (first-order leveling benchmark GPS coincident point), ensuring reliable and accurate fitting at the location. Figure 1 shows the position distributions in the experimental and test areas. This study used the first-order benchmark (78 positions) GPS position data, which contained both the ellipsoidal height $h$ and benchmark orthometric height $H$. The digital terrain model of the test area is shown in Figure 2.

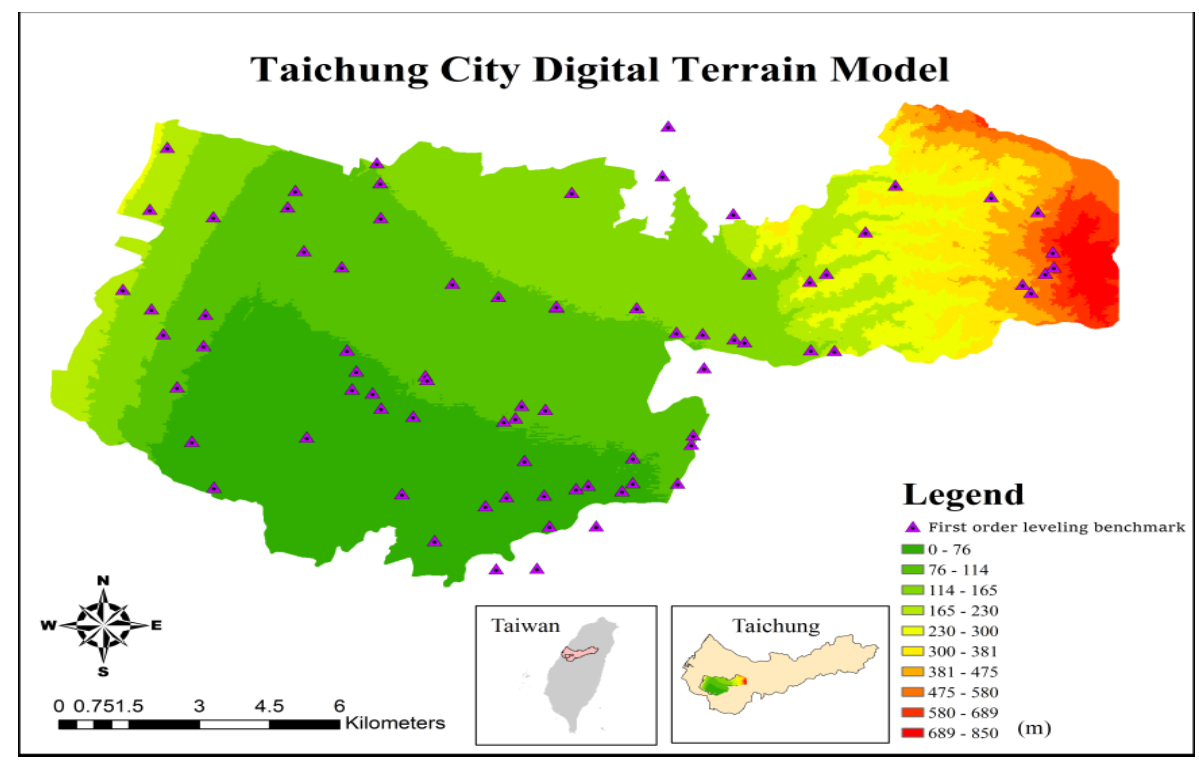

Figure 2: Digital terrain model map of the test area (unit: $\mathrm{m}$ ).

\subsection{Data Processing}

The step-by-step procedures for data collection and processing are as follows.

(a) Collect the GPS measurement results: Obtain the GPS and first-order level measurements of the 78 known benchmarks to determine both the ellipsoidal height $h$ and direct benchmark orthometric height $H$ for these positions.

(b) Preprocess the data: Create a text file containing the coordinates and geoid value $N$ data of the 78 positions to input into the program.

(c) Determine the quadratic polynomial function coefficients: Use MATLAB to program the PSO model to identify coefficients fitting the local geoid model.

(d) Optimization fitting: Select partial positions as the fitting positions and regard the remaining positions as checkpoints. Use the RMSE values as the accuracy comparison standard for evaluating the differences between the geoid undulations and checkpoints. 
Select the position distribution and quantity of fitting points during the fitting process to determine the optimal number of positions for the PSO algorithm.

(e) Results analysis: For accuracy standard determination, identify the difference between the direct level elevation $H$ and orthometric height $H$ by using the fitting method.

(f) Establish a local geoid undulation model: GPS can be employed for general leveling when the accuracy of a test area geoid undulation model established according to the fitting results satisfies the accuracy standard.

\subsection{Global Optimization Test and Analysis of the PSO Fitting Results}

This section describes determining the optimal number of fitting points with the PSO method to test the local geoid undulation model of the test area. Twenty known and well-distributed firstorder benchmarks in the test area and the perimeter values were selected as the known fitting points, and two first-order benchmarks located in the test area were added with each iteration to conduct the calculation. The selected positions were set as the fitting points, and the remaining positions were considered checkpoints; PSO was used to calculate coefficients to fit the local geoid and compute $\triangle \mathrm{N}$ RMSE of the checkpoints, which was used as the accuracy evaluation standard to identify the best-fitting number of points in the test area. Because these checkpoints were not included in the fitting, their validation is regarded as external, providing more convincing results. The results of the test area optimization experiment revealed that the RMSE increased as the number of fitting points increased from 20 to 30, with the maximum value observed at Point 30, resulting in minimal accuracy. From Points 30 to 52, the RMSE exhibited an inverse relationship with the number of points. The minimum error was achieved at Point 52, and became irregular between Points 52 and 60. Thus, this study performed local geometric geoid fitting on the entire test area by using 52 points; the remaining 26 points were employed as checkpoints to verify the fitting results (Table 1), as shown in Figure 3.

Table 1 : RMSE of the various fitting point obtained using PSO

\begin{tabular}{c|c|c|c}
\hline No. of Fitting points & RMSE of $\Delta N(\mathrm{~cm})$ & No. of Fitting points & RMSE of $\Delta N(\mathrm{~cm})$ \\
\hline 20 & \pm 2.64 & 42 & \pm 2.76 \\
\hline 22 & \pm 2.80 & 44 & \pm 2.71 \\
\hline 24 & \pm 2.85 & 46 & \pm 2.66 \\
\hline 26 & \pm 2.94 & 48 & \pm 2.66 \\
\hline 28 & \pm 2.94 & 50 & \pm 2.60 \\
\hline 30 & \pm 2.97 & 52 & \pm 2.58 \\
\hline 32 & \pm 2.93 & 54 & \pm 2.63 \\
\hline 34 & \pm 2.92 & 56 & \pm 2.67 \\
\hline 36 & \pm 2.87 & 58 & \pm 2.63 \\
\hline 38 & \pm 2.85 & 60 & \pm 2.62 \\
\hline 40 & \pm 2.81 & & \\
\hline
\end{tabular}




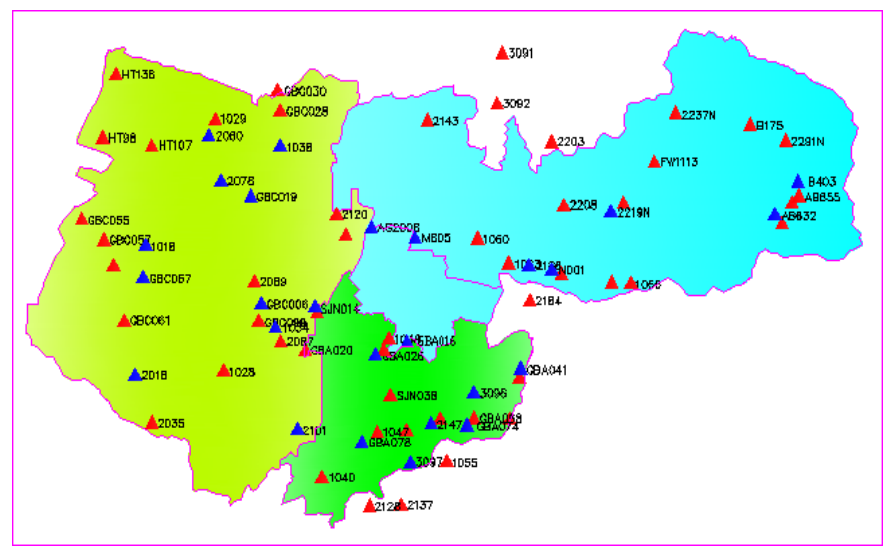

Figure 3 : Distributed graph of the fitting points and checkpoints in the test area

The undetermined coefficients $a_{0}, a_{1}, a_{2}, a_{3}, a_{4}, a_{5}$ were first calculated using PSO with the quadratic surface-fitting method, and then used to solve the local geoid values of all 78 points. The position distributions are shown in Figure 3; the red points denote the fitting points and the blue points denote checkpoints. The checkpoint results are listed in Table 2, where $N_{l}$ represents the fitting geoid values, $N_{0}$ represents the known tested geoid values, and $\Delta \mathrm{N}$ represents the difference between the fitting geoid values and the known tested geoid values.

Table 2 : Geoid height difference between the fitting values and known checkpoint values.

\begin{tabular}{c|c|c|c|c|c|c|c}
\hline Point name & N0 $(\mathrm{m})$ & N1 $(\mathrm{m})$ & $\Delta \mathrm{N}(\mathrm{cm})$ & Point name & N0 $(\mathrm{m})$ & $\mathrm{N} 1(\mathrm{~m})$ & $\Delta \mathrm{N}(\mathrm{cm})$ \\
\hline GBC006 & 19.491 & 19.478 & 1.30 & 2186 & 20.032 & 20.017 & 1.50 \\
\hline 2101 & 19.552 & 19.551 & 0.10 & N001 & 20.092 & 20.075 & 1.70 \\
\hline GBC019 & 19.444 & 19.448 & -0.40 & AB632 & 20.707 & 20.695 & 1.20 \\
\hline 3096 & 19.912 & 19.889 & 2.30 & $2219 \mathrm{~N}$ & 20.229 & 20.229 & 0.00 \\
\hline 2060 & 19.402 & 19.372 & 3.00 & 1034 & 19.496 & 19.502 & -0.60 \\
\hline GBA026 & 19.674 & 19.686 & -1.20 & M805 & 19.766 & 19.765 & 0.10 \\
\hline GBA016 & 19.728 & 19.749 & -2.10 & 2147 & 19.785 & 19.798 & -1.30 \\
\hline 2078 & 19.407 & 19.398 & 0.90 & GBA078 & 19.667 & 19.664 & 0.30 \\
\hline 1018 & 19.321 & 19.292 & 2.90 & 3097 & 19.774 & 19.758 & 1.60 \\
\hline GBC067 & 19.305 & 19.296 & 0.90 & GBA041 & 19.985 & 19.993 & -0.80 \\
\hline SJN014 & 19.571 & 19.571 & 0.00 & GBA074 & 19.9 & 19.871 & 2.90 \\
\hline AG2008 & 19.67 & 19.673 & -0.30 & B403 & 20.771 & 20.775 & -0.40 \\
\hline 1038 & 19.507 & 19.497 & 1.00 & 2018 & 19.319 & 19.304 & 1.50 \\
\hline
\end{tabular}

Because the test area is classified as gentle terrain, the geoid undulation exhibited a gradual and nearly parallel positive trend. As demonstrated by the data in Figure 2 and Table 2, the fitting geoid value $\mathrm{N} 1$ of the algorithm exhibited a minimum of $19.292 \mathrm{~m}$ at Point 1018 and a maximum of $20.775 \mathrm{~m}$ at Point B403. The average geoid value was $20.033 \mathrm{~m}$. These findings indicated that the test area had a gradual and level surface. The calculations results further indicated that the positions were evenly and accurately distributed, satisfying the general accuracy requirement for fitting local geoid models and providing a rapid method for determining geoid values and orthometric heights.

The PSO-fitted geoid value and corresponding known measured geoid mean value was $1.16 \mathrm{~cm}$, with a checkpoint RMSE of $\pm 1.02 \mathrm{~cm}$, and maximum and minimum inferior values of 2.96 and $0.01 \mathrm{~cm}$, respectively. We also do a test without PSO just use quadratic polynomial function. The corresponding known measured geoid mean value was $1.85 \mathrm{~cm}$, with a checkpoint RMSE of 
$\pm 2.75 \mathrm{~cm}$, and maximum and minimum inferior values of 6.36 and $-0.01 \mathrm{~cm}$ (Table 3). PSO yielded an acceptable fitting accuracy for the entire area.

Table 3 : Geoid height difference between the fitting values and known checkpoint values with and without PSO.

\begin{tabular}{c|c|c}
\hline & $\begin{array}{c}\text { Quadratic polynomial } \\
\text { function with PSO }\end{array}$ & $\begin{array}{c}\text { Quadratic polynomial } \\
\text { function }\end{array}$ \\
\hline \hline$\Delta N$ maximum $(\mathrm{cm})$ & 2.96 & 6.36 \\
\hline$\Delta N$ minimum $(\mathrm{cm})$ & 0.01 & -0.01 \\
\hline Mean $(\mathrm{cm})$ & 1.16 & 1.85 \\
\hline RMSE $(\mathrm{cm})$ & \pm 1.02 & \pm 2.75 \\
\hline
\end{tabular}

\section{CONCLUSIONS}

The results of this study are summarized into the following two findings:

(a) The PSO algorithm was used to conduct global fitting calculations with 78 points included 26 checkpoints. The checkpoint RMSE was $\pm 1.02 \mathrm{~cm}$; thus, the geoid undulation model of the test area established in this study is practicable.

(b) The PSO algorithm does not necessitate that the solution for determining other parameters be determined before performing the fitting procedure. The execution time is short. Specifically, the geoid undulation of the fitting point or checkpoint can be determined within $3 \mathrm{~s}$ and used to obtain the RMSE of the checkpoint. The operating interface is user friendly, and the fitting process can be rapidly and easily performed.

\section{REFERENCES}

Abdalla, A. and Green, C. "Utilisation of Fast Fourier Transform and Least-squares Modification of Stokes formula to compile a gravimetric geoid model over Khartoum State: Sudan." Arabian Journal of Geosciences, 2016.

Abdalla, A . and Elmahal, A. "Augmentation of vertical accuracy of digital elevation models using Gaussian linear convolution filter." Conference of Basic Sciences and Engineering Studies (SGCAC), 2016.

Abdalla, A . et al. "The Evaluation of The New Zealand's Geoid Model Using the KTH Method." Geodesy and Cartography, Vol.37, No.1, p.5-14, 2011.

Abdalla, A . and FAIRHEAD, D."A new gravimetric geoid model for Sudan using the KTH method." Journal of African Earth Sciences 60 (4), 213-221, 2011.

Abdalla, A. "Determination of a gravimetric geoid model of Sudan using the KTH method." MSc thesis, Royal Institute of Technology (KTH),2009. 
Akcin, H. and Celik, C. T. "Performance of Artificial Neural Networks on Kriging Method in Modeling Local Geoid.” Boletim de Ciências Geodésicas.Vol.19, No.1, p.84-97,2013.

DARAS, I. "Determination of a Gravimetric Geoid Model of Greece Using the Method of KTH.” MSc thesis, Royal Institute of Technology (KTH), 2008.

Eberhart, R. C., AND SHI, Y. "Comparison between genetic algorithms and particle swarm optimization.” Evolutionary Programming VII: 611-616, 1998.

Ellmann, A. "Least squares modification of Stokes formula with applications to the Estonian geoid." Licentiate thesis, Royal Institute of Technology (KTH),2001.

Featherstone, W. E. et al. "Comparison of Remove-Compute-Restore and University of New Brunswick Techniques to Geoid Determination over Australia, and Inclusion of Wiener-Type Filters in Reference Field Contribution." Journal of Surveying Engineering, Vol.130, No.1, ASCE, p.40-47, 2004.

Kao, S. P. et al. "USING A LEAST SQUARES SUPPORT VECTOR MACHINE TO ESTIMATE A LOCAL GEOMETRIC GEOID MODEL." Boletim de Ciências Geodésicas , 2014, 20.2: 427-443.

Kao, S. P., "A Study of Using Different Methods to Determine Local Geoid Model-A Case Study of Taichung City." Journal of the Chinese Institute of Engineers, Vol.23, No.2, p223228,2006 .

Kao, S. P. and BETHEL, J.S. "Geoid from Geopotential Model in the Taiwan Area." Marine Geodesy, Vol.15, No.4, pp.245-252,1992(a).

Kao, S. P. and BETHEL, J.S “A Study of the Gravimetric Geoid in the Taiwan Area." Presented in the ASPRS-ACSM Annual Convention, Albuquerque, 1992(b).

Kennedy, J. and EBERHART, R. "Particle Swarm Optimization." IEEE International of first Conference on Neural Networks, 1995: 167-171.

Kiamehr, R. "Precise Gravimetric Geoid Model for Iran Based on GRACE and SRTM Data and the Least-Squares Modification of Stokes' Formula: with Some Geodynamic Interpretations." $\mathrm{PhD}$ thesis, Royal Institute of Technology (KTH), 2006.

Kotsakis, C. and Sideris, M. G. "On the adjustment of combined GPS/levelling/geoid networks." Journal of Geodesy, Volume 73, Issue 8, pp 412-421, 1999.

Lin, L. S., "Application of Back-Propagation Artificial Neural Network to Regional Grid-Based Geoid Model Generation Using GPS and Leveling Data." Journal of Surveying Engineering , Vol.133, No.2, ASCE, p.81-89, 2007.

Ning, F. S. "USING SURFACE FITTING AND BUFFER ANALYSIS TO ESTIMATE REGIONAL GEOIDAL UNDULATION.” Boletim de Ciências Geodésicas , 2015, 21.3: 624636.

Odera, P.A., Musyoka, S.M. AND Gachari, M.K. "Practical application of the geometric geoid for heighting over Nairobi County and its Environs." Journal of Agriculture, Science and Technology, Vol. 16, No. 2, p. 175-185, 2014

Shen, Y. T. "A Study of Fitting Local Geoid Model by Least Squares Support Vector MachineA Case Study of Taichung Area." Thesis, Department of Civil Engineering, National Chung Hsing University, 2011(in Chinese). 
Tranes, M. D. et al. "Comparisons of GPS-Derived Orthometric Heights Using Local Geometric Geoid Models.” Journal of Surveying Engineering , Vol.133, No.1, ASCE, p.6-13, 2007.

Ulotu, P. "Geoid Model of Tanzania from Sparse and Varying Gravity Data Density by the KTH Method." PhD thesis, Royal Institute of Technology (KTH),2009.

Ustun, A. and Demirel, H. "Long-Range Geoid Testing by GPS-Leveling Data in Turkey." Journal of Surveying Engineering, Vol.132, No.1, ASCE, p.15-23, 2006.

You, R. J. "Local Geoid Improvement Using GPS and Leveling Data: Case Study." Journal of Surveying Engineering, Vol.132, No.3, ASCE, p.101-107, 2006.

Yang, Z.. J. and Chen, Y. Q. "Determination of local geoid with geometric method: Case study." Journal of Surveying Engineering 125.3 (1999): 136-146.

Recebido em 20 de abril de 2016.

Aceito em 27 de setembro de 2016. 